\title{
Low-quality lower lobes—discard, repair, or only use the good rest?
}

\author{
Konrad Hoetzenecker, MD, PhD, and Walter Klepetko, MD
}

\author{
From the Division of Thoracic Surgery, Medical University of Vienna, Vienna, Austria. \\ Disclosures: Authors have nothing to disclose with regard to commercial support. \\ Received for publication March 21, 2018; accepted for publication March 27, 2018; available ahead of print May \\ $10,2018$. \\ Address for reprints: Konrad Hoetzenecker, MD, PhD, Division of Thoracic Surgery, Department of Thoracic Sur- \\ gery, Vienna Lung Transplant Program, Medical University of Vienna, Waehringer Guertel 18-20, Vienna \\ 1090, Austria (E-mail: konrad.hoetzenecker@meduniwien.ac.at). \\ J Thorac Cardiovasc Surg 2018;156:e39-40 \\ $0022-5223 / \$ 36.00$ \\ Copyright (c) 2018 by The American Association for Thoracic Surgery \\ https://doi.org/10.1016/j.jtcvs.2018.03.106
}

We read with great interest the case report published by Otani and colleagues ${ }^{1}$ in this issue of The Journal of Thoracic and Cardiovascular Surgery. The authors describe a novel technique of lobar transplantation using both upper lobes of a donor and combining them to a left-sided single-lung transplant. Despite the complexity of the technical procedure, the patient had an uneventful perioperative course. The authors are to be congratulated for their technical finesse and for further enlarging the spectrum of surgical options using different combinations of donor lobes for transplantation.

In fact, the described situation of good-quality upper lobes in the presence of impaired lower lobes is not an infrequent finding during procurements, and too often results in nonacceptance of the entire graft. It is the merit of the authors to describe a new technical approach, which makes the utilization of the unimpaired upper lobes possible. The described technique adds another variation to the hitherto existing concepts of using isolated pulmonary lobes for transplantation. It builds on previous work describing adult lobar transplantation, ${ }^{2}$ lung bipartitioning, ${ }^{3}$ and replacement of only a lobe instead of the whole lung. ${ }^{4}$

However, unless the lower lobes are not grossly consolidated by pneumonia, "resuscitation" by ex vivo lung perfusion (EVLP) should be taken into consideration as well. Improvement of organ function in more than $60 \%$ of cases has been described. ${ }^{5}$ In addition, separate assessment of function and quality of all 5 different lobes is possible during EVLP, which facilitates the ultimate decision to accept or decline borderline-quality lobes for transplantation. ${ }^{6}$ Another novel approach, to especially address the problem of impaired lower lobes, would be prone positioning of the graft during EVLP, which has recently been described in a porcine model.

There is of course no clear answer, which of these approaches, the EVLP repair option, or the technically challenging implantation variant, is better and the final judgement must be left to the individual surgeon. However, cavities. medicine.

\section{References} discussion 369-70.

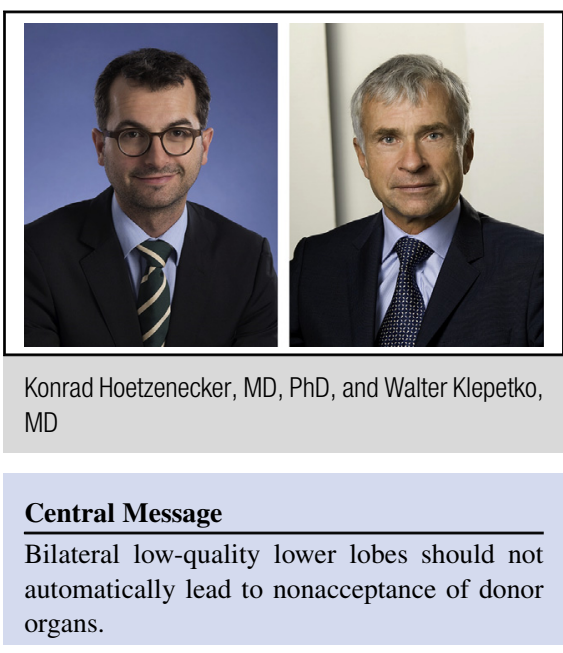

See Article page e35.

the risks that are inherent to each method have to be calculated carefully and despite the excellent result reported by Otani and colleagues, potential technical hazards associated with such an advanced technique should not be underestimated. These range from a doubled risk for bronchial healing, potential kinking of the vessels, to limitations in the applicability of this technique for patients with large chest

Whatever the preference might be, maximal lung protective intraoperative handling is required to avoid additional damage during the implantation. In this context, use of venoarterial extracorporeal membrane oxygenation, which has been shown to provide optimal controlled reperfusion conditions throughout the transplantation, should be considered.

In conclusion, the authors have to be congratulated on adding a new brick to the building of lung transplantation, and for providing further evidence that innovation necessarily happens outside the area of evidence-based

1. Otani S, Kurosaki T, Sugimoto S, Yamane M, Oto T. Unilateral lung transplantation using intact bilateral upper lobes. J Thorac Cardiovasc Surg. 2018;156:e35-8.

2. Mitilian D, Sage E, Puyo P, Bonnette P, Parquin F, Stern M, et al. Techniques and results of lobar lung transplantations. Eur J Cardiothorac Surg. 2014;45:365-9;

3. Couetil JP, Tolan MJ, Loulmet DF, Guinvarch A, Chevalier PG, Achkar A, et al Pulmonary bipartitioning and lobar transplantation: a new approach to donor organ shortage. J Thorac Cardiovasc Surg. 1997;113:529-37. 
4. Aoyama A, Chen F, Minakata K, Yamazaki K, Yamada T, Sato M, et al. Sparing native upper lobes in living-donor lobar lung transplantation: five cases from a single center. Am J Transplant. 2015;15:3202-7.

5. Cypel M, Keshavjee S. Extending the donor pool: rehabilitation of poor organs. Thorac Surg Clin. 2015;25:27-33.

6. Schweiger T, Benazzo A, Lang G, Matilla JR, Klepetko W. Selective lobar exclusion by venous clamping during ex vivo lung perfusion. J Thorac Cardiovasc Surg. 2017; 154:e87-9.
7. Niikawa H, Okamoto T, Ayyat KS, Itoda Y, McCurry KR. F12. The protective effect of prone positioning on porcine lungs during ex vivo lung perfusion. Presented at: AATS 98th Annual Meeting; May 1, 2018; San Diego, CA.

8. Hoetzenecker K, Schwarz S, Muckenhuber M, Benazzo A, Frommlet F, Schweiger $\mathrm{T}$, et al. Intraoperative ECMO and the possibility of postoperative prolongation improve survival in bilateral lung transplantation. J Thorac Cardiovasc Surg. 2018;155:2193-206.e3. 